\title{
ANALISIS ATRIBUT SUPERMARKET TERHADAP LOYALITAS KONSUMEN PADA SUPERMARKET CHANDRA TANJUNG KARANG BANDAR LAMPUNG
}

\author{
Tiar Mirnasari

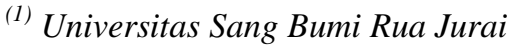 \\ *emailtiarmirnasari2021@gmail.com
}

\begin{abstract}
Abstrak. Atribut supermarket menjadi perangsang motif pembelanja membeli produk. Hipotesis yang dirumuskan adalah atribut supermarket memiliki pengaruh yang signifikan terhadap loyalitas konsumen di Chandra Supermarket Tanjung Karang Bandar Lampung. Setelah dianalisis diperoleh hasil bahwa variable atribut supermarket memiliki pengaruh positif terhadap loyalitas konsumen di Chandra Supermarket Tanjung Karang Bandar Lampung dapat diterima dengan pengaruh sebesar 17,4\% dengan probabilitas signifikasi sebesar 0,000 yang kurang dari 0,050. Saran yang diajukan adalah manajemen Chandra Supermarket harus terus mencari cara untuk mendapatkan penilaian yang memuaskan dari setiap konsumen maupun calon konsumen baik melalui variable atribut supermarket maupun faktor lain yang berpengaruh dengan cara kualitas produk yang baik, produk-produk yang ditawarkan sangat lengkap, mudah untuk melihat varian produk yang ditawarkan serta harga yang terjangkau, lebih murah dengan produk kompetitor lain merupakan faktor yang sangat kuat dalam mempengaruhi tingkat loyalitas konsumen sehingga mendapatkan kesesuaian harapan dan penilaian yang terbaik demi terwujudnya loyalitas konsumen.
\end{abstract}

Kata kunci: Atribut Supermarket, Loyalitas Konsumen

Abstract. Supermarket attributes are the motives for stimulating shoppers to buy products. The hypothesis formulated is that supermarket attributes have a significant influence on consumer loyalty at Chandra Supermarket Tanjung Karang Bandar Lampung. After analyzing the results that the supermarket attribute variable has a positive influence on consumer loyalty at Chandra Supermarket Tanjung Karang Bandar Lampung it can be accepted with an influence of $17.4 \%$ with a significance probability of 0.000 which is less than 0.050. The suggestion put forward is that Chandra Supermarket management must continue to look for ways to get satisfactory product quality from each consumer and prospective consumer through supermarket variables and other factors that influence the way of good product quality, the products offered are very complete, easy to see. product variants offered at affordable prices, cheaper factors with other product competitors are very strong in influencing the level of consumer loyalty so that they get the best hopes and expectations for the realization of consumer loyalty.

Keywords: Supermarket Attributes, Consumer Loyalty

\section{PENDAHULUAN}

Pemasaran adalah suatu sistem dari kegiatan bisnis yang dirancang untuk memenuhi kebutuhan pasar dengan barang atau jasa dengan merencanakan, menentukan harga, mempromosikan dan mendistribusikan barang-barang yang dapat memuaskan keinginan dan mencapai pasar sasaran serta tujuan perusahaan (Kotler, 2005:10). Berdasarkan pengertian tersebut dapat dikatakan bahwa kegiatan pemasaran saat ini tidak hanya terfokus pada kegiatan jua-beli barang atau jasa, tetapi juga merupakan proses menciptakan nilai bagi pelanggannya. Nilai inilah yang akan 
menciptakan hubungan timbal balik yang saling menguntungkan bagi kedua belah pihak. Dalam kondisi persaingan yang semakin kompetitif saat ini, halu tama yang harus diprioritaskan oleh perusahaan adalah kepuasan pelanggan agar perusahaan dapat bertahan, bersaing dan menguasai pangsa pasar.

Untuk memenangkan persaingan yang semakin kompetitif diantara pelak uindustri ritel dan meraih pangsa pasar, diperlukan suatu strategi pemasaran ritel yang baik. Pelaku ritel harus berusaha menetapkan strategi pemasaran agar mencapai kepuasan pelanggan yang tinggi sehingga mengakibatkan pelanggan menjadi loyal. Menurut James F. Engle, Blackwell dan Miniard (1994:36) "loyalitas konsumen adalah kesetiaan konsumen akan suatu barang atau jasa dengan melakukan pembelian ulang barang atau jasa tersebut secara terus menerus".

Adapun yang membuat loyal konsumen terdiri dari dua faktor, yaitu faktor internal supermarket dan factor psikologis konsumen itu sendiri. Faktor internal supermarket adalah beberapa keunggulan atribut supermarket dalam menarik loyalitas konsumen untuk berbelanja di supermarket tersebut. Sedangkan factor eksternal psikologis adalah factor perilaku konsumen dalam diri pelanggan itu sendiri yang ikut berkontribusi terhadap loyalitas konsumen.

Dalam hal ini atribut supermarket merupakan salah satu stimulus yang meliputi factor Ambient, Design dan Social. Ambient adalah kenyamanan suasana yang dirasakan pembelanja saat mengamati barang dan jasa yang ditawarkan. Design adalah rancangan fisik supermarket yang meliputi tatanan layout dan fungsinya, tanda dan simbol, keindahan seperti tatanan warna dan visual yang memberikan kenyamanan kepada pembelanja termasuk penempatan posisi escalator, lift dan elemen arsitek lainnya. Social adalah faktor yang berkaitan dengan keberadaan karyawan dan pembelanja lainnya dalam supermarket yang bersangkutan, (Donovan et al, 2002:346).

Berikut ini data kunjungan konsumen di supermarket Chandra Tanjung Karang Bandar Lampung.

Tabel 1.Data Kunjungan Chandra Supermarket 2016-2020

\begin{tabular}{ccc} 
Tahun & Konsumen & $\begin{array}{c}\text { Pertumbuhan } \\
\text { Per Tahun }\end{array}$ \\
\hline 2016 & 21.824 .117 & - \\
2017 & 22.592 .951 & $3,52 \%$ \\
2018 & 22.231 .246 & $-1,60 \%$ \\
2019 & 25.612 .484 & $15,21 \%$ \\
2020 & 29.818 .752 & $16,42 \%$ \\
\hline
\end{tabular}

Sumber: data Chandra Supermarket, 2021

Tabel 1 menunjukkan bahwa kunjungan konsumen di Chandra mengalami tren yang baik, tetapi sempat mengalami penurunan dari tahun 2017 ke 2018 sebanyak $-1,60 \%$.walaupun sempat mengalami penurunan namun penurunannya tidak terlalu signifikan seab pada tahun berikutnya jumlah konsumen terus meningkat.

Chandra supermarket menyediakan tempat yang nyaman untuk bersosialisasi saat bertemu dengan teman, saudara atau partner kerja, dimana tidak hanya tempat untuk belanja tetapi terdapat tempat-tempat yang disediakan untuk bersantai atau makan Bersama. Supermarket ini menawarkan produk yang berkualitas, desain interior yang menarik, filosofi pelayanan, komunikasi yang baik, serta suasananya dengan music yang membuat nyaman konsumen sehingga konsumen dapat dengan santai untuk berbelanja.

Chandra supermarket membuat kartu VIP untuk para member konsumen Chandra, ini dikarenakan untuk membuat loyalitas terhadap konsumen. Dengan kartu tersebut konsumen mandapat poin yang dapat ditukar dengan barang yang sesuai konsumen inginkan. Tidak hanya kartu VIP, pihak Chandra pun membuat undian 
yang diadakan 3 kali setiap tahun dengan berhadiah mobil dan rumah sebagai hadiah utama, serta memberikan jaminan terhadap produk-produknya mempunyai kualitas yang baik sehingga tidak perlu ragu untuk membelinya. Berikutini data konsumen member VIP di Chandra Supermarket Tanjung Karang Bandar Lampung:

Tabel 2. Data Kunjungan Chandra Supermarket 2016-2020

\begin{tabular}{ccc}
\hline Tahun & Konsumen & $\begin{array}{c}\text { Pertumbuhan } \\
\text { Per Tahun }\end{array}$ \\
\hline 2016 & 424.236 & - \\
2017 & 442.430 & $4,29 \%$ \\
2018 & 463.736 & $4,81 \%$ \\
2019 & 482.361 & $4,01 \%$ \\
2020 & 502.568 & $4,19 \%$ \\
\hline
\end{tabular}

Sumber: data Chandra Supermarket, 2021

Tabel 2 menunjukkan bahwa Chandra Supermarket mengalami peningkatan member VIP setiap tahunnya. Meskipun persentase jumlah member VIP ditahun 2019 sempat mengalami penurunan namun penurunannya tidak terlalu signifikan sebab pada periode tahun berikutnya jumlah member VIP terus meningkat.

Sehubungan dengan masalah di atas maka peneliti tertarik untuk melakukan penelitian Pengaruh Atribut Supermarket Terhadap Loyalitas Konsumen Chandra Supermarket Tanjung Karang Bandar Lampung.

\section{METODE PENELITIAN}

Jenis penelitian yang digunakan.adalah.deskriptif dan analitis. Desain deskriptif untuk menemukan fakta dengan interpretasi yang tepat, sementara desain analitis untuk menguji hipotesis dan mengadakan interpretasi yang lebih dalam tentang hubungan-hubungan. Variabel bebas dalam penelitian ini adalah atribut supermarket, sedangkan untuk variable terikatnya adalah loyalitas konsumen. Data yang dikumpukan dalam penelitian ini adalah data primer dan dikumpulkan dengan metode wawancara dan kuesioner.

Pada dasarnya populasi menurut Sugiyono (2010:80) adalah wilayah generalisasi yang terdiri atas objek atau subjek yang memiliki kualitas dan karakteristik tertentu yang diterapkan peneliti untuk dipelajari kemudian ditarik kesimpulannya. Dari pengertian tersebut dalam penelitian ini adalah konsumen Chandra Supermarket yang terletak di Jl. Hayam Wuruk Pemuda I Tanjung Karang Bandar Lampung yang meliputi konsumen yang datang langsung.

Sampel menurut Sugiyono (2010:81) adalah proses memilih jumlah elemen populasi yang cukup agar dengan meneliti sampel dan memahami sifat dan karakteristik sampel peneliti dapat menggeneralisasikan sifat dan karakteristik populasi. Teknik sampling yang dipakai pada penelitian ini adalah Teknik sampling menurut Sugiyono (2010:68) yaitu purposive sampling, Teknik pengambilan sampel sumber data dengan pertimbangan tertentu yang memiliki informasi yang cukup untuk diteliti.

Perumusan Teknik pengambilan sampling Berdasarkan (Widiyanto, 2008:19):

Keterangan :

$$
n=\frac{Z^{2}}{4(M o e)^{2}}
$$

$n \quad=$ Jumlah sampel

$Z$ = tingkat keyakinan yang dibutuhkan

Dalam penentuan sampel sebesar 95\% 1,96

Moe = Margin of error atau kesalahan maksimal yang biasa ditoleransi, biasanya $10 \%$

Maka:

$$
\begin{aligned}
& n=\frac{Z^{2}}{4(M o e)^{2}} \\
& n=\frac{1,96^{2}}{4(0,10)^{2}}
\end{aligned}
$$




$$
n=96,04
$$

Berdasarkan hasil perhitungan di atas maka jumlah sampel yang digunakan adalah 96,04 atau 96 kemudian dibulatkan menjadi 100 berdasarkan hasil perhitungan, maka jumlah sampel yang akan digunakan sebanyak 96,04 responden dan dibulatkan menjadi 100 responden yang merupakan konsumen Chandra Supermarket Tanjung Karang Bandar Lampung.

Data diolah dengan menggunakan uji-t (t-test). Penelitian ini menggunakan analisis regresi linier dengan rumus sebagai berikut:

$$
Y=a+b X+e
$$

Keterangan:

$X=$ Atribut supermarket

$Y=$ Loyalitas konsumen

$a=$ Konstanta dari persamaan regresi

$b=$ Koefisien regresi dari variabel atribut supermarket

$e=$ Variabel error

Uji ini dilakukan untuk mengetahui apakah secara parsial/individual variable bebas $(\mathrm{X})$ berpengaruh secara signifikan terhadap variable terikat $(\mathrm{Y})$. perumusan hipotesisnya adalah sebagai berikut:

$\mathrm{H}_{0}: \beta_{\mathrm{i}}=0$, tidak ada pengaruh $\mathrm{X}$ terhadap $\mathrm{Y}$ $\mathrm{H}_{1}: \beta_{\mathrm{i}}>0$,ada pengaruh positif $\mathrm{X}$ terhadap Y

Kriteria yang digunakan: Jika propbabilitas $>0,05$ maka $\mathrm{H}_{0}$ diterima. Jika probabilitas $<0,05$ maka $\mathrm{H}_{0}$ ditolak dan $\mathrm{H}_{1}$ diterima.Sedangka $t_{\text {tabel }}$ dengan signifikansi 0,05 dan $\mathrm{df}=\mathrm{n}-\mathrm{k}=100-3=97$ sebesar 1,661.Semua perhitungan tersebut dianalisis dengan bantuan program SPSS version 20.0 for windows.

\section{HASIL DAN PEMBAHASAN}

\section{Hasil}

Jumlah sampel yang diambil sebanyak 100 responden, pengumpulan data dilakukan dengan melakukan penyebaran langsung pada konsumen yang datang pada Chandra Supermarket Tanjung Karang Bandar Lampung yang sesuai syarat dan karakeristik responden yang dibutuhkan meliputi jenis kelamin, usia, Pendidikan dan pekerjaan.

Tabel 4. Karakteristik Responden Berdasarkan Jenis Kelamin

\begin{tabular}{ccc}
\hline Jenis & Frekuensi & Prosentase \\
Kelamin & & \\
\hline Laki-laki & 27 & $27 \%$ \\
Perempuan & 73 & $73 \%$ \\
\hline
\end{tabular}

Dari table tersebut dapat kita lihat bahwa jumlah responden Wanita lebih dominan dibandingkan laki-laki. Hal ini dapat dijadikan referensi bahwa ibu-ibu atau perempuan memiliki peranan penting dalam pemilihan tempat belanja di Chandra Supermarket Tanjung Karang Bandar Lampung.

Tabel 5. Karakteristik Responden Berdasarkan Usia

\begin{tabular}{ccc}
\hline Usia & Frekuensi & Prosentase \\
\hline$<20$ tahun & 6 & $6 \%$ \\
$15-20$ tahun & 18 & $18 \%$ \\
$21-30$ tahun & 21 & $21 \%$ \\
$31-40$ tahun & 26 & $26 \%$ \\
$>40$ tahun & 29 & $29 \%$ \\
\hline
\end{tabular}

Dari table terlihat bahwa karakteristik responden Berdasarkan usia sangat variative dari segala usia didominasi oleh konsumen dengan usia lebih dari 40 tahun. Hal ini cukup membuktikan bahwa jasa pelayanan Chandra Supermarket Tanjung Karang Bandar Lampung mampu menumbuhkan kepercayaan dan memiliki daya Tarik tersendiri bagi para konsumen untuk segala usia. Melalui hal ini juga sebaiknya pihak Chandra Supermarket semakin tanggap dengan keinginankeinginan yang kritis dari para konsumen yang terdiri dari berbagai usia tesebut. Yaitu dengan cara penyediayaan fasilitas layanan berupa pemberian informasi yang lengkap dan mudah dimengerti. 
Tabel 6. Karakteristik Responden Berdasarkan Pendidikan

\begin{tabular}{ccc} 
Pendidikan & Frekuensi & Prosentase \\
\hline SMA & 17 & $17 \%$
\end{tabular}

Dari tabel 6 terlihat bahwa karakteristik responden Berdasarkan Pendidikan sangat variatif dan didominasi oleh konsumen dengan Pendidikan S1 sebesar 56\%. Hal ini membuktikan bahwa Chandra Supermarket mempunyai citra dan image yang baik dimata konsumen.

Tabel 7. Karakteristik Responden Berdasarkan Pekerjaan

\begin{tabular}{ccc}
\hline Pekerjaan & Frekuensi & Prosentase \\
\hline Wirausaha & 20 & $20 \%$ \\
Pegawai Swasta & 23 & $23 \%$ \\
Pegawai Negeri & 22 & $22 \%$ \\
Mahasiswa & 18 & $18 \%$ \\
Lainnya & 17 & $17 \%$ \\
\hline
\end{tabular}

\begin{tabular}{ccc}
\hline S1 & 56 & $56 \%$ \\
S2 & 22 & $22 \%$ \\
Lainnya & 5 & $5 \%$ \\
\hline
\end{tabular}

Dari tabel di atas dapat diketahui bahwa pegawai swasta merupakan jenis pekerjaan terbanyak yang berkunjung di Chandra Supermarket dengan jumlah 23 orang akan tetapi itu bukan angka yang terlalu dominan dikarenakan responden dari profesi yang lain juga berjumlah hamper sama dan variasi. Hal ini membuktikan bahwa pengunjung Chandra Supermarket bukan hanya dari kalangan tertentu akan tetapi dari semua kalangan masyarakat sehingga dapat memberikan nilai lebih yang bisa meningkatkan loyalitas konsumen secara signifikan.

Hasil uji hipotesis variabel atribut supermarket terhadap loyalitas konsumen dapat kita lihat dalam tabel di bawah ini:

Coefficients $^{\mathrm{a}}$

Tabel 8. Hasil Uji t

\begin{tabular}{|c|c|c|c|c|c|c|}
\hline \multirow{2}{*}{\multicolumn{2}{|c|}{ Model }} & \multicolumn{2}{|c|}{ Unstandardized Coefficients } & $\begin{array}{l}\text { Standardized } \\
\text { Coefficients }\end{array}$ & & \multirow[b]{2}{*}{ Sig. } \\
\hline & & B & Std. Error & Beta & $\mathrm{t}$ & \\
\hline 1 & (Constant) & -912 & 1.343 & & -.679 & .499 \\
\hline & $\begin{array}{l}\text { Atribut } \\
\text { Supermarket }\end{array}$ & .073 & .035 & .174 & 2.058 & .042 \\
\hline
\end{tabular}

a. Dependent Variable: LoyalitasKonsumen

Dari tabel di atas dapat disimpulkan bahwa variabel $\mathrm{X}$ (atribut supermarket) menghasilkan $t_{\text {hitung }}$ sebesar 2,058 dengan probalilitas signifikansi $0,000 . \mathrm{T}_{\text {hitung }}>\mathrm{t}_{\text {tabel }}$ dan probabilitas signifikansi memiliki nilai kurang dari $0,05(<0,05)$, maka $\mathrm{H}_{0}$ ditolak dan $\mathrm{H}_{1}$ diterima. Dengan demikian maka secara parsial/individual variabel $\mathrm{X}$ (atribut supermarket) berpengaruh positif secara nyata terhadap variabel $\mathrm{Y}$ yaitu loyalitas konsumen.

\section{Pembahasan}

Berdasarkan analisis menggunakan metode regresi linier dengan menggunakan SPSS didapat bahwa variable atribut supermarket berpengaruh positif terhadap loyalitas konsumen Chandra Supermarket Tanjung Karang Bandar Lampung secara parsial, pernyataan ini sesuai dengan penelitian Hartono Subagio (2011) serta Jeslyn Monica Leha (2014) yang menyatakan bahwa atribut supermarket berpengaruh terhadap loyalitas konsumen.

Variabel atribut supermarket memiliki koefisien regresi sebesar 17,4. Hal ini mengidentifikasikan bahwa Chandra Supermarket perlu meningkatkan atmosfer yang baik yaitu design supermarket yang 
menarik serta display produk yang menarik, fasilitas tempat parkir yang memadai, layanan karyawan yang ramah dan cepat merespon dan membantu konsumen yang membutuhkan serta varian produk yang ditawarkan supermarket beragam. Hal ini apabila dilakukan dengan baik dan konsisten akan mampu meningkatkan loyalitas konsumennya.

Dengan terjaganya loyalitas konsumen, manajemen dapat membuat Chandra Supermarket ini dapat terus berkembang, dapat bersaing dengan competitor, dan memiliki nilai perusahaan yang meningkat. Meningkatkan loyalitas konsumen dapat dengan berinteraksi atau menjalin komunikasi dengan baik dengan para konsumen, mengetahui apa yang menjadi keinginannya, menerima kritikan dan masukan konsumen, merancangkan program-program peduli kemanusiaan seperti memberikan harga murah bagi konsumen yang tidak mampu dengan persyaratan yang tidak sulit, sehingga terjalin ikatan yang kuat antara Chandra Supermarket dan konsumen, maka sedikit banyak akan memberikan kesesuaian harapan serta memunculkan persepsi yang baik.

\section{KESIMPULAN}

Berdasarkan hasil analisis yang diperoleh dari penelitian yang telah dilakukan, maka dapat disimpulkan beberapahal sebagai berikut:

1. Penilaian dan respon konsumen terhadap atribut supermarket adalah konsumen rata-rata menjawab 4 yang merupakan setuju dikarenakan design menarik, display produk tersusun rapih, lokasi supermarket strategis, fasilitas parker memadai serta mendapatkan diskon dengan pembayaran kartu member VIP.

2. Variabel atribut supermarket memiliki pengaruh sebesar 17,4\% terhadap loyalitas konsumen Chandra Supermarket Tanjung Karang Bandar Lampung.

\section{DAFTAR PUSTAKA}

Engel, James F., Blackwell. Roger D., Miniard, P.W.1994. Consumer Behaviour. Orlando The Dryden Press: USA

Kotler, Philip. 2005."Marketing Management", Eleventh Edition, New Jersey: Prentice Hall

O’Donovan, Garry.2002. Environmental Disclosure in The Annual Report Extending The Applicability and Predictive Power of Legitimacy Theory. Accounting Journal, Vol.15, No.3 pp.227-239

Sugiyono, 2010. Metode Penelitian KuantitatifKualitatif dan RND. Alfabeta: Bandung

Widiyanto, Ibnu. 2008. Pointers: Metodologi Penelitian. BP UNDIP: Yogyakarta 